\title{
Predictors of Survival in a Huntington's Disease Population from Southern Italy
}

\author{
Carlo Rinaldi, Elena Salvatore, Ilaria Giordano, Sara De Matteis, Tecla Tucci, \\ Valeria Russo Cinzia, Fabiana Rossi, Imma Castaldo, Vincenzo Brescia Morra, \\ Luigi Di Maio, Alessandro Filla, Giuseppe De Michele
}

\begin{abstract}
Background: The primary aim of the present study was to determine the survival rates and identify predictors of disease duration in a cohort of Huntington's disease (HD) patients from Southern Italy. Methods: All medical records of HD patients followed between 1977 and 2008 at the Department of Neurological Sciences of Federico II University in Naples were retrospectively reviewed and 135 patients were enrolled in the analysis. At the time of data collection, 41 patients were deceased (19 males and 22 females) with a mean \pm SD age at death of 56.6 \pm 14.9 years (range 18-83). Results: The median survival time was 20 years (95\% CI: 18.3-21.7). Cox regression analysis showed that the number of CAG in the expanded allele (HR 1.09 for 1 point triplet increase, $\mathrm{p}=0.002$ ) and age of onset (HR 1.05 for 1 point year increase, $\mathrm{p}=0.022$ ) were independent and significant predictors of lower survival rates. Conclusions: We believe that these findings are important for a better understanding of the natural history of the disease and may be relevant in designing future therapeutic trials.
\end{abstract}

RÉSUMÉ: Indicateurs de survie dans une population atteinte de la maladie de Huntington résidant dans le sud de l'Italie. Contexte : Le but principal de cette étude était de déterminer le taux de survie et d'identifier les indicateurs de durée de la maladie dans une cohorte de patients atteints de la maladie de Huntington (MH) suivis entre 1977 et 2008. Méthode : Tous les dossiers médicaux des patients atteints de la MH suivis entre 1977 et 2008 au département des sciences neurologiques de l'Université Federico II de Naples ont été révisés rétrospectivement et les données recueillies chez 135 patients ont été analysées. Au moment de l'étude, 41 patients étaient décédés (19 hommes et 22 femmes) dont l'âge moyen au moment du décès était de 56,6 ans (ET 14,9 ans - âges extrêmes 18 à 83 ans). Résultats : Le temps de survie médian était de 20 ans (IC à 95\%: 18,3 à 21,7). L'analyse de régression de Cox a montré que le nombre de répétitions CAG dans l'allèle porteur d'une expansion (RR 1,09 pour 1 point d'augmentation du triplet, $\mathrm{p}=0,002)$ et l'âge de début (RR 1,05 pour 1 point d'augmentation de l'année, $\mathrm{p}=0,022$ ) étaient des indicateurs indépendants significatifs d'un taux de survie plus bas. Conclusions : Nous croyons que ces constatations aident à mieux comprendre l'histoire naturelle de la maladie et peuvent être pertinentes lors de la conception d'essais thérapeutiques.

Can. J. Neurol. Sci. 2012; 39: 48-51

Huntington's Disease (HD) is an autosomal-dominant neurodegenerative disorder caused by an expanded CAG repeat in exon 1 of the huntingtin gene (HTT) which encodes a stretch of glutamines in the huntingtin protein. ${ }^{1}$ The mean age of onset is in the fourth decade ${ }^{2}$ and the size of the CAG repeats sequence in the mutant allele is inversely related to the age at onset. ${ }^{3}$ Several studies also support a positive correlation between the size of the expanded repeats and the rate of disease progression. ${ }^{4-}$ ${ }^{6}$ Recently, the triplet size in the normal allele has been shown to play a role in modulating the clinical severity and progression of HD as well. ${ }^{7}$

Whether the size of the CAG repeat expansion also has an impact on the survival time, is still an unanswered question. Lack of long term follow-up studies in genetically defined HD populations and failure to use survival analysis methodology may have contributed to leave this issue unsolved.

In the current study, we examined rates and predictors of survival in a population of 135 HD patients, particularly focusing on the relationship between $\mathrm{CAG}$ repeat size and disease duration.

\section{Patients and Methods}

Study population. We retrospectively reviewed all medical records of HD patients followed between 1977 and 2008 at the

From the Department of Neurological Sciences (CR, ES, IG, TT, VRC, FR, VBM, LDM, AF, GDM) and Department of Cellular and Molecular Biology (IC), IEOS CNR, Università Federico II, Naples; Department of Occupational and Environmental Health (SDM), Università degli Studi di Milano and Epidemiology Unit Department of Preventive Medicine, Fondazione IRCCS Ca' Granda - Ospedale Maggiore Policlinico, Milan, Italy.

Received May 18, 2011. Final Revisions Submitted July 11, 2011.

Correspondence to: Carlo Rinaldi, Department of Neurological Sciences, University of Federico II, Via Pansini, 5, 80121 - Napoli, Italy. Email: rinaldi.ca@gmail.com 
Department of Neurological Sciences of Federico II University in Naples, which is a referral center for HD.

Inclusion criteria were manifest signs and symptoms of the disease and positive molecular testing for the presence of a CAG triplet number $>39$ in the HD gene.

For all cases, sociodemographic and clinical data (date of birth, sex, age and symptoms at onset, and sex of affected parent) were collected at the first full evaluation by a neurologist experienced in movement disorders. Most of the treating physicians and the ones reviewing the medical records of the patients included are the authors of the present study. Age of onset was based on first appearance of motor changes (chorea, dystonia, bradykinesia), psychiatric disturbances (personality changes, psychosis), memory decline, or a combination of these symptoms. For subjects manifesting the disease after 2001 $(n=35)$, motor onset was considered only when the signs were unequivocally related to HD with a confidence in the diagnosis of $99 \%$ based on the Unified Huntington's Disease Rating Scale (UHDRS). Depression and anxiety, despite often affecting preclinical and early phase patients, 8,9 were not considered onset symptoms, because of their high prevalence in HD families and in the general population. Some patients with motor onset symptoms were under psychotropic medication for depression or anxiety at the time of the diagnosis.

The DNA for genetic diagnosis was extracted from venous lymphocytes after collection of informed consent from all the patients. Genetic testing for HD was performed according to published methods. ${ }^{10}$ Follow-up was carried on until December 2008 , or through death age for deceased patients. Information about the date and the causes of death were obtained from spouses or first-degree relatives by a personal interview.

Standard protocol approvals, registrations, and patient consent. The study was approved by the Federico II University Ethics Committee.

Statistical analysis. Descriptive statistics are presented as mean \pm standard deviation (SD) for continuous variables and proportions for categorical variables. The two group comparisons of categorical or continuous variables for demographic and clinical features were performed using $\chi^{2}$ or Fisher exact test and Wilcoxon rank sum test. Regression analysis was performed to examine relations between variables.

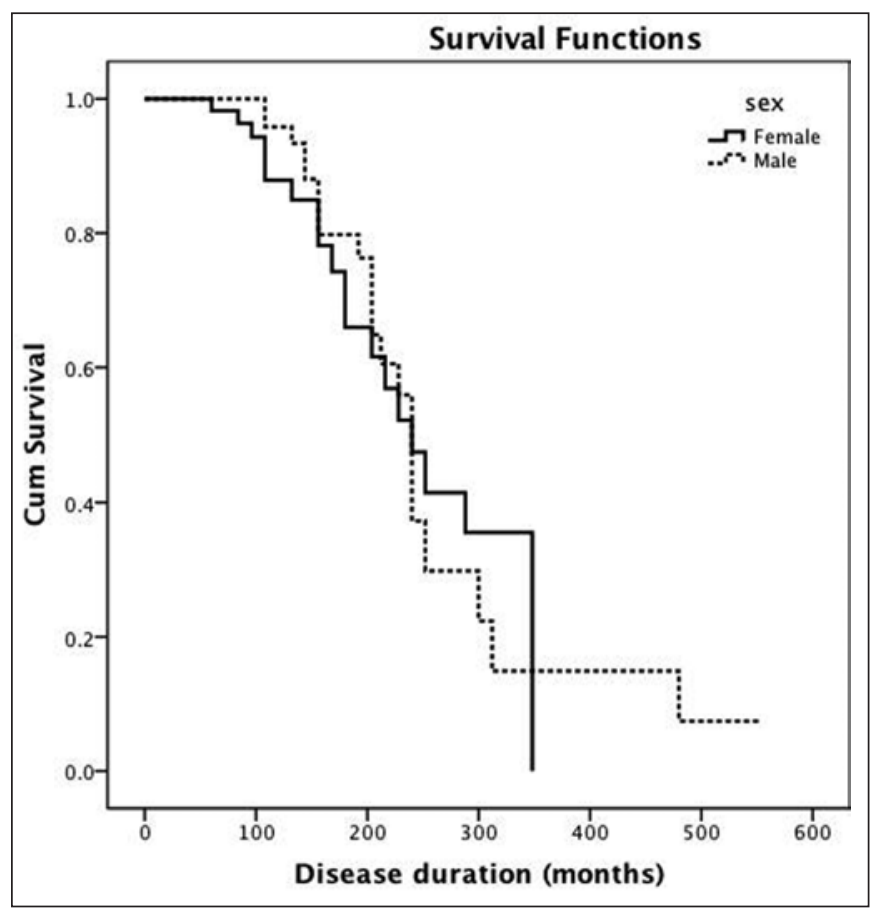

Figure: Kaplan-Meier survival curve of Huntington's disease patients according to sex.

A regression model was fit with the size of the expanded allele as independent variable and the natural log of age of onset as dependent variable, as published elsewhere. ${ }^{3}$ Survival was defined as the time in months between onset and death or last assessment in 2008 for censored patients.

The analyses were graphically represented by Kaplan-Meier curves and the statistical comparison of the survival curves was performed with the log-rank test. Cox proportional hazards modeling was used to examine factors related to survival. A likelihood ratio test was used to compare the fit of the models. All tests were two-sided with a significance level of 0.05 . Statistical analyses were performed using SPSS software, version 18 (SPSS, Inc., 2009, Chicago, IL)

Table 1: Characteristics of the patients included in the study

\begin{tabular}{l|l}
\hline Patients, $\mathrm{n}$ & 135 \\
\hline M/F & $65 / 70$ \\
\hline Onset age, y & $40.95 \pm 13.03(6-70)$ \\
\hline Symptoms at onset, \% & Mo: $58 \% ;$ Ps: $19 \% ;$ Cogn: $2 \% ;$ Mx: $21 \%$ \\
\hline Mutant CAG repeat size & $45.77 \pm 5.64(39-92)$ \\
\hline Wild type CAG repeat size & $18.74 \pm 3.81(9-37)$ \\
\hline Affected father, $\mathrm{n}(\%)$ & $60(44 \%)$ \\
\hline
\end{tabular}

Mo, Motor; Ps, Psychiatric; Cogn, Cognitive; Mx, Mixed; n, number; m, male; f, female; y, years; * Data are indicated as mean $\pm \mathrm{SD}$ (range) 
Table 2: Predictors of survival from Cox proportional hazards model

\begin{tabular}{l|c|c|c|c|c|c}
\hline & \multicolumn{3}{|c|}{ Age scale } & \multicolumn{3}{c}{ Disease scale } \\
\hline \multicolumn{1}{c|}{ Variable } & HR & $95 \% \mathrm{Cl}$ & $\mathrm{p}$ & $\mathrm{HR}$ & $95 \% \mathrm{Cl}$ & $\mathrm{p}$ \\
\hline Sex & 1.01 & $0.50-1.97$ & 0.98 & 1.02 & $0.52-2.00$ & 0.95 \\
\hline Onset age & 0.92 & $0.88-0.96$ & 0.00 & 1.05 & $1.01-1.08$ & 0.02 \\
\hline CAG length MT allele & 1.29 & $1.14-1.46$ & 0.00 & 1.09 & $1.04-1.15$ & 0.00 \\
\hline CAG length WT allele & 0.98 & $0.89-1.08$ & 0.75 & 1.00 & $0.91-1.10$ & 0.92 \\
\hline
\end{tabular}

Model was adjusted for symtoms at onset. HR=Hazard Ratio; MT=Mutant; WT=wild type; CI=confidence interval

\section{RESULTS}

Of 138 subjects, three refused to participate and the remaining 135 were included in the study. The clinical characteristics of the included patients are summarized in table 1. All patients were heterozygous for the triplet expansion in the HD gene. Only one patient also carried in the wild type allele a number of triplets in the reduced penetrance range (37 CAG repeats).

A significant inverse correlation was found between CAG expansion of the mutant allele and the natural log of age at onset $\left(\mathrm{R}^{2}=0.57 ; \mathrm{p}<0.001\right)$. The mean $\pm \mathrm{SD}$ follow-up time after diagnosis was $145 \pm 90$ months (range 12-552). No statistical differences in CAG repeat sizes in both alleles, onset age, disease duration, death age, and number of deaths were found between males and females (data not shown). At the time of data collection, 41 patients were deceased (19 males) with a mean \pm SD age at death of $56.6 \pm 14.9$ years (range 18-83). The reported causes of death were pneumonia $(42 \%)$, cardiovascular complications (26\%), aspiration followed by asphyxia (14\%), cachexia (6\%), falls (3\%), and suicide (3\%). In the remaining cases information on the primary cause of death was unspecified. The median survival time was 20 years (95\% CI: 18.3-21.7). No difference in survival estimates for time from symptom onset was registered between genders ( $\mathrm{p}=0.85$ ) (Figure).

Also no differences in survival rates were found according to onset phenotype $(\mathrm{p}=0.79)$, sex of the affected parent $(\mathrm{p}=0.30)$, and when patients were categorized into three age groups: $\leq 20$ $(\mathrm{n}=6$, range: $6-20), 21-49(\mathrm{n}=89), \geq 50(\mathrm{n}=40$, range: 50-70) $(\mathrm{p}=0.51)$.

The following variables were considered in the proportional hazard model: sex, symptoms at onset, reported causes of death, the size of the wild type and the expanded CAG repeats and age of onset. Patients were found to have a higher risk of death for every unit increase of CAG triplet size in the expanded allele (HR 1.09 for 1 point triplet increase, $\mathrm{p}=0.002$ ) and age of onset (HR 1.05 for 1 point year increase, $\mathrm{p}=0.022$ ) (Table 2). Schoenfeld residuals investigation showed no violation of the proportional hazards assumption.

A supplementary model was run including the interaction between the CAG triplets in both alleles. The interaction was not significant (HR 0.99, 95\% CI 0.98-1-00, p=0.39) and was excluded from the final model.
To further explore the role of cardiovascular causes of death as a confounding factor for reduced survival in older age patients, we explored the age at death and CAG repeat expansion between patients dead for cardiovascular vs non-cardiovascular reasons, but found no difference $(\mathrm{p}=0.22$ and $\mathrm{p}=0.17$ respectively).

\section{Discussion}

Aim of our study was to analyze the survival and the predictors of survival in a genetically confirmed population of HD patients.

The formal diagnosis of HD is currently made on the basis of the presence of an otherwise unexplained extrapyramidal movement disorder in a person with a positive family history, confirmed by gene testing. However, there is increasing recognition of subtle cognitive and behavioral symptoms happening years before. ${ }^{11,12}$ Since it is also likely that the optimum point at which to introduce neuroprotective drugs to slow the rate of disease progression is the early stage, we decided to use a broader definition of disease onset. Interestingly, no difference in survival rate was found according to onset phenotype.

Pneumonia and heart failure were the most frequent leading to death causes in our series, similarly to a previous report on 395 HD patients. ${ }^{13}$ The observed frequency of suicides is also similar to that reported by others..$^{14,15}$

Our findings demonstrate that the CAG repeat length in the mutant allele is a significant predictor of survival in HD. A previous study on $121 \mathrm{HD}$ patients followed for an average of 8.5 years showed a slightly, not significantly shorter survival for patients carrying larger $\mathrm{CAG}$ repeats $(\mathrm{HR}=2.4, \mathrm{p}=0.071){ }^{16}$

Older onset age of $\mathrm{HD}$, when treated as a continuous variable, also predicted shorter disease duration, which may be explained by an additional effect of the shorter life expectancy inherent to old age. This latter finding is similar to that found by some researchers, ${ }^{17,18}$ not by others. ${ }^{19}$ The reason for these discrepancies could be the lack of inclusion of very late onset patients. Interestingly, both CAG repeat length and age of onset remained significant predictors of survival, also when other potential confounding factors were included in the Cox model.

Whether patients with juvenile onset also have a reduced survival is still debated, ${ }^{18,20,21}$. No reduced survival was found in 
patients with disease onset $<20$ years in our cohort, even though it must be taken into account that the number of cases was very small $(n=6)$.

Several issues of this study deserve comments. First, because most of the patients come from the same area, the extent to which our findings can be generalized is uncertain. Second, the retrospective data collection is a potential limitation. Third, ages of onset and data about the causes of death may be inaccurate.

Nevertheless, so far this is the longest survival analysis study in a genetically confirmed population of HD patients. Since the knowledge of the natural history and of the variables that have an impact on the survival is essential for counseling of patients and design of future therapeutic trials in HD, larger population-based studies comprising detailed and standardized phenotypic information will be required in the future to validate or modify our conclusions.

\section{AKNOWLEDGEMenT}

The authors thank the patients and their families for their participation in the study and the European Huntington's Disease Network (Euro-HD) for the support.

\section{REFERENCES}

1. The Huntington's Disease Coll Group. A novel gene containing a trinucleotide repeat that is expanded and unstable on Huntington's disease chromosomes. Cell. 1993;72:971-83.

2. Harper B. Huntington disease. J R Soc Med. 2005;98:550.

3. Langbehn DR, Brinkman RR, Falush D, Paulsen JS, Hayden MR. A new model for prediction of the age at onset and penetrance for Huntington's disease based on CAG length. Clin Genet. 2004; 65:267-77.

4. Ravina B, Romer M, Constantinescu R, et al. The relationship between CAG repeat length and clinical progression in Huntington's disease. Mov Disord. 2008;23:1223-7.

5. Aziz NA, van der Burg JM, Landwehrmeyer GB, et al. Weight loss in Huntington disease increases with higher CAG repeat number. Neurology. 2008;71:1506-13.

6. Rosenblatt A, Liang KY, Zhou H, et al. The association of CAG repeat length with clinical progression in Huntington disease. Neurology. 2006;66:1016-20.

7. Aziz NA, Jurgens CK, Landwehrmeyer GB, et al. Normal and mutant HTT interact to affect clinical severity and progression in Huntington disease. Neurology. 2009;73:1280-5.
8. Paulsen JS, Nehl C, Hoth KF, et al. Depression and stages of Huntington's disease. J Neuropsychiatry Clin Neurosci. 2005; 17:496-502

9. Marshall J, White K, Weaver M, et al. Specific psychiatric manifestations among preclinical Huntington disease mutation carriers. Arch Neurol. 2007;64:116-21.

10. Andrew SE, Goldberg YP, Theilmann J, Zeisler J, Hayden MR. A CCG repeat polymorphism adjacent to the CAG repeat in the Huntington disease gene: implications for diagnostic accuracy and predictive testing. Hum Mol Genet. 1994;3:65-7.

11. Tabrizi SJ, Langbehn DR, Leavitt BR, et al. Biological and clinical manifestations of Huntington's disease in the longitudinal TRACK-HD study: cross-sectional analysis of baseline data. Lancet Neurol. 2009;8:791-801.

12. Paulsen JS, Langbehn DR, Stout JC, et al. Detection of Huntington's disease decades before diagnosis: the Predict-HD study. J Neurol Neurosurg Psychiatry. 2008;79:874-80.

13. Sorensen SA, Fenger K. Causes of death in patients with Huntington's disease and in unaffected first degree relatives. J Med Genet. 1992;29:911-4.

14. Schoenfeld M, Myers RH, Cupples LA, et al. Increased rate of suicide among patients with Huntington's disease. J Neurol Neurosurg Psychiatry. 1984;47:1283-7.

15. Farrer LA. Suicide and attempted suicide in Huntington disease: implications for preclinical testing and persons at-risk. Am J Med Genet. 1986;24:305-11.

16. Pekmezovic T, Svetel M, Maric J, et al. Survival of Huntington's disease patients in Serbia: longer survival in female patients. Eur J Epidemiol. 2007;22:523-6.

17. Roos RA, Hermans J, Vegter-van der Vlis M, van Ommen GJ, Bruyn GW. Duration of illness in Huntington's disease is not related to age at onset. J Neurol Neurosurg Psychiatry. 1993;56: 98-100.

18. Foroud T, Gray J, Ivashina J, Conneally PM. Differences in duration of Huntington's disease based on age at onset. J Neurol Neurosurg Psychiatry. 1999;66:52-6.

19. Myers RH, Madden JH, Teague JL, Falek A. Factors related to onset age in Huntington's disease. Am J Hum Genet. 1982;34: 481-8.

20. Newcombe RG, Walker DA, Harper PS. Factors influencing age at onset and duration of survival in Huntington's chorea. Ann Hum Genet. 1981;45:387-96.

21. Roos RAC, Hermans J, Vegter-van der Vlis M, et al. Duration of illness in Huntington's disease is not related to age at onset. J Neurol Neurosurg Psychiatry. 1993;56:9. 